\title{
Pattern of Use, Awareness of Health Hazards, and Effect on Family Relationships among Saudi Blackberry Users
}

\author{
Hanem F. Mohamed, ${ }^{(1,2)}$ Manal Al Shehri, ${ }^{(3)}$ Sultan S. Almaiman, ${ }^{(4)}$ Fajr \\ Almutairi, ${ }^{(3)}$ and Bassayl Al-Dossari, ${ }^{(3)}$ \\ ${ }^{1}$. Assistant Professor, College of Nursing, King Saud Bin Abdul Aziz University for Health Sciences, Riyadh, \\ KSA. \\ 2. Assistant Professor, College of Nursing, Medical Surgical Nursing Department, Tanta University, Egypt. \\ 3. Nursing Student, College of Nursing, King Saud Bin Abdul Aziz University for Health Sciences, Riyadh, KSA \\ 4. College of Medicine, King Saud Bin Abdul Aziz University for Health Sciences, Riyadh, KSA
}

\begin{abstract}
:
Introduction: One of the life style changes that happened in the Saudi community recently is the widespread use of Smartphones especially the Blackberry $(B B)$. Although, the BB has fewer features than other Smartphones, it is used extensively for communication and business. Studies have shown that all kinds of cellular phones have negative effect on health and interrupt family relationships. The objectives of this study were to assess the pattern of use of BB phones, explore people's awareness of health hazards associated with their use, and investigate the effect of BB use on family relationships among Saudi people.

Methods: Descriptive cross sectional design was used with a convenience sample of 473 participants. Data were collected from the community at Riyadh Shopping Malls and Students at KSAU-HS. Inclusion criteria were the ability to read and write Arabic and to have a BB phone. Eligible participants were asked to provide a consent after explaining the purpose of the study and agreeing to participate. The questionnaire consisted of demographic data and data about pattern of use, awareness of health hazards associated with BB use and questions about effect on family relationships. It was developed in English, then translated into Arabic because data were collected in Arabic. The questionnaire was piloted for applicability before data collection and then modified.

Results: $66 \%$ of participants were male, $31 \%$ were below the age of 20 years old and $64 \%$ were in the age group 21 to 40 years old. $71 \%$ were university graduates, and $31 \%$ working in specialty work. Regarding the pattern of BB use, majority reported that their BB phone was very important to them, they use them most of the time (during classes, breaks, meal time) and internet connection on their phone is important. During sleep, majority keep their phones close to bed and even under the pillow. 54\% of participants know and $45 \%$ do not know that using BB phones too much would cause health problems. MVA, headache, vision and hearing problems were reported as health hazards that would be associated with the use of the BB phones. In Addition, almost half of participants reported that they chat while sitting with their families and during meal time while they know that extensive use of $B B$ would affect family relationships.

Conclusion and recommendation: Although, a considerable number of Saudis are aware that Blackberries might cause health problems, and might affect family relationships, they use them in a broad pattern. A strategy to assess perception and attitude are critical to increase people's awareness about effective use of such devices. Assessment of health hazards associated with the addiction of BB use is helpful toward building positive attitudes and improving the health of the Saudi population.
\end{abstract}

Keywords: Pattern, awareness, health hazards, family relationships

\section{Introduction}

One of the lifestyle changes that happened recently in the Saudi community is the widespread use of Smartphones especially the blackberry (BB). Although the BB has fewer features than other Smartphones, it is used extensively for communication, business and much more. Studies in Saudi Arabia showed that the number of BB users and sales have been widely increased at the end of 2009 (Kibi, 2010). Additionally, the number of users who access the Internet through cell phones has increased to 9 million (Alzoman \& Albagami, 2010). Studies have shown negative effects of all kinds of cellular phones use on people's health (Pendse, N. and Zagade, D. 2012; Chai, Chai and Tan 2000). The wide spread use of BB among Saudi people has caused social changes at all age groups and among families. Research on the effect of these technology on Saudi community is crucial in order to understand social changes in morals and behaviors that Saudis encounter for proper handling and management. The objective of this study was to: Assess the pattern of BB use among people in 
the Saudi community, explore people awareness of health hazards associated with BB use, and investigate the effects of the BB use on family relationships among Saudi people. BB phones was chosen because it was so popular at the time of data collection and their prices was affordable among different social levels.

\section{Methods}

Design: A descriptive cross-sectional deign was used in this study.

Sample/settings: A convenience sample 473 participants were surveyed from the community (Riyadh Shopping Malls, and King Saud Bin Abdul-Aziz University for Health Science, Riyadh, KSA). Data were collected from November 2012 to January 2103. Inclusion criteria were adult, able to read and write Arabic, have a Blackberry phone, and agree to participate in the study.

Procedure of data collection and ethical considerations: Approval to approach participants was obtained from authorized personnel at the shopping malls before the start of the data collection. Eligible subjects were approached by the researchers, purposes of the study were explained and those who agree to participate were asked to sign a consent. Students from KSAU-HS were approached at their breaks and were asked to provide consent after voluntarily agreeing to participate. Survey was distributed and investigators were available to answer participants' questions in a semi structured interview. Participants were told that their participation is voluntary and that they have the right to withdraw at any time. They were also told that numbers will be used instead of names to keep their anonymity and nobody would access their data.

Questionnaire: The questionnaire included 4 parts, first is the demographic profile of participants such as age, gender, education and occupation. Second part is the pattern of BB use questionnaire that include questions related to importance of $\mathrm{BB}$ use, time of use, purposes of uses, and language used for chatting and texting. Third part is the awareness of health hazards associated with BB use which include 2 questions that explain awareness of health hazards and most common health problems associated with BB use from the opinion of participants. The forth part is the effect of using the BB on family relationships. The questionnaire was developed by the researchers after reviewing based related research. The questionnaire was piloted for applicability and visibility, and modified before use. Reliability of the questionnaire was tested before data analysis and Cronbach's alpha was reported as .79.

\section{Results}

Results showed that $66 \%$ of participants were males and $34 \%$ were females. $64 \%$ were in the age group of 21 to 40 years old and $31 \%$ were 20 years old and younger. $71 \%$ were university graduates and $19 \%$ were school students. $32 \%$ were working in a specialty kind of works, $19 \%$ working in office and administrative kinds of works and $49 \%$ do not work. Demographic data are presented in Table 1.

Table 1: Demographic characteristics of the study participants

\begin{tabular}{|l|l|}
\hline Item & $\begin{array}{l}\text { Percentages } \\
(\mathrm{N}=473)\end{array}$ \\
\hline Age & \\
$<20$ years & $31 \%$ \\
$21-40$ & $64 \%$ \\
$>41$ & $5 \%$ \\
\hline Gender & \\
Male & $66 \%$ \\
Female & $34 \%$ \\
\hline Education & \\
University graduates & $71 \%$ \\
School students & $19 \%$ \\
Not educated & $10 \%$ \\
\hline Occupation & \\
Specialty work & $32 \%$ \\
Office/administrative & $19 \%$ \\
Not working & $49 \%$ \\
\hline
\end{tabular}

Regarding the pattern of BB use, results showed that majority of participants $(88 \%)$ reported that their phone is very important to them, $73 \%$ reported that they use the BB phone most of the time, $77 \%$ of them indicated that they use BB for chatting, and $45 \%$ said that the internet in their phone is essential for them.

Regarding the time that they use their BB phones, results displayed that $41 \%$ of participants can use their phones during classes, $32 \%$ use their phones most of the time because they are not working, $20 \%$ use their phone during their breaks, $5 \%$ use their phones before they go to sleep and after they wake up before getting out of bed and $2 \%$ provided mixed answer. Regarding where people keep the BB phone during their sleep, results indicated that $54 \%$ of participants keep their phones close to their beds, $25 \%$ put them under their pillows, $14.5 \%$ put their phones far from their beds and $7 \%$ turn them off during their sleep. 
Responses to a question that asks about using the BB phone during meal time portrayed that $43 \%$ finish their chatting first then eat, $31 \%$ eat and chat at the same time, $19 \%$ eat fast in order to chat, and $7 \%$ finish their chatting first then eat. Regarding recharging the internet connection of BB phone users, participants reported that $57 \%$ recharge the internet connection on their phone immediately after the connection ends, $22 \%$ recharge internet connection on their phone on a monthly bases, $11 \%$ recharge internet a while after it ends and $10 \%$ have a regular continuous internet connection on their phones. Regarding the language that participants mainly use for text messaging on their BB phones, results reported that $63 \%$ use the Arabic Language, 29\% use English Language and $8 \%$ use a mixed language. Regarding the broadcasting advertisements that participants receive on their phones and if they confirm them or decline them. Results indicated that $38 \%$ sometimes trust these broadcasting messages, $36 \%$ do not trust these broadcasting messages, and $25 \%$ always trust these messages. In addition, $43 \%$ decline the broadcasting messages they receive and $41 \%$ sometimes confirm these messages. Results about the pattern of BB use are presented in figures 1, 2, 3, 4, 5, and 6 .

Figure 1:

Pattern of BB use

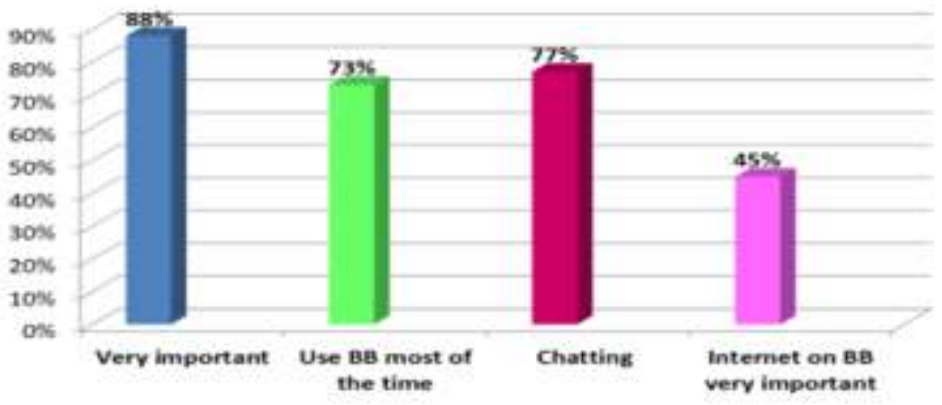

Figure 2:

Time using BB
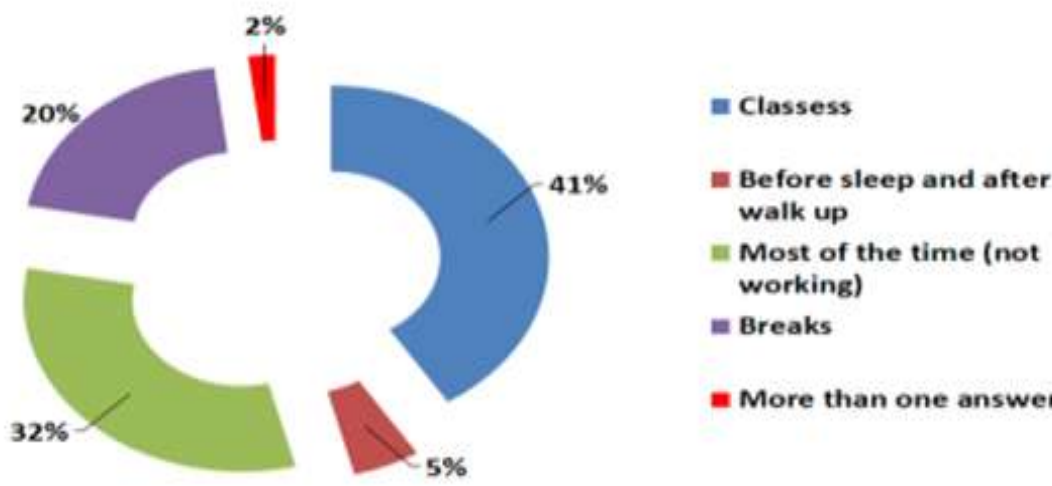

- More than one answer

Figure 3.

\section{During Sleep}

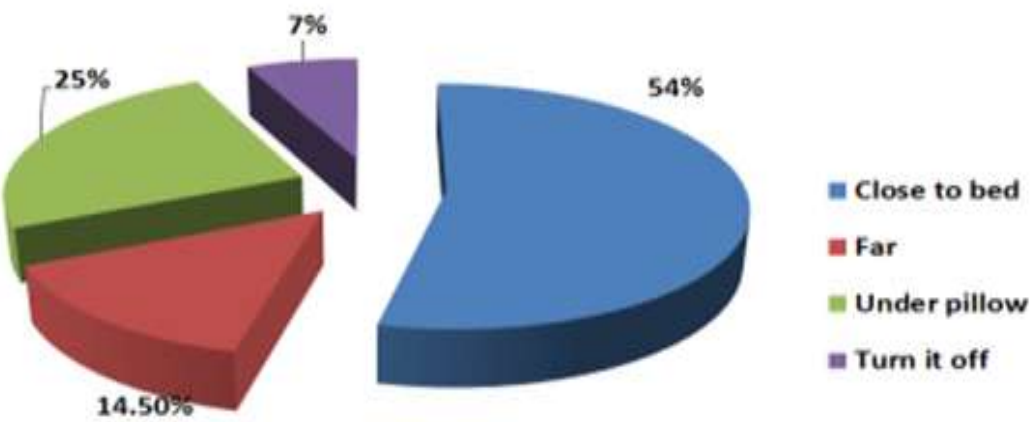


Figure 4:

BB use Regarding Meal Time

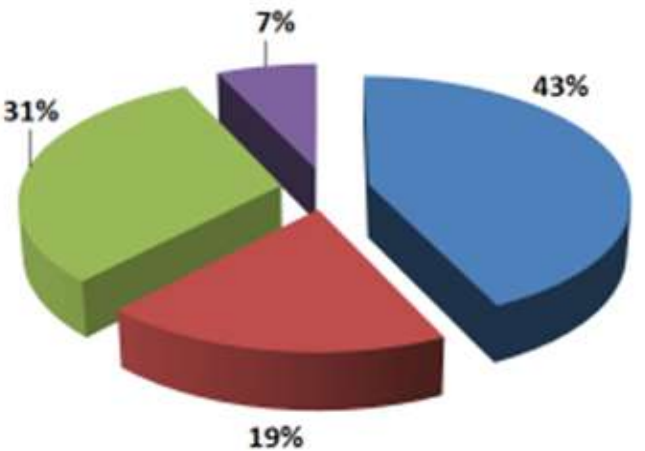

Figure 5:
E Finish chat and eat

Eat fast then chat

Eat and chat at the same

time

Eat later

Recharging the Internet on $\mathrm{BB}$

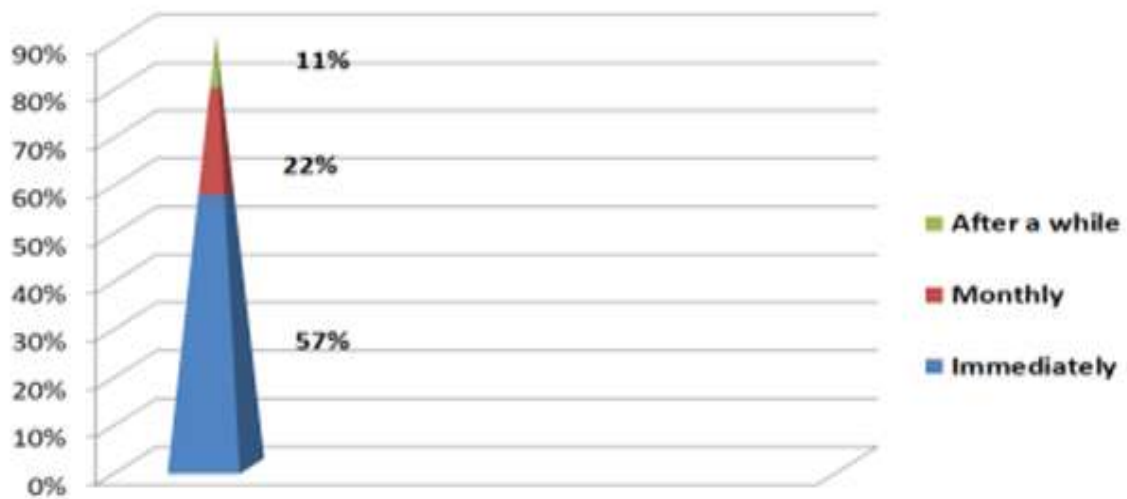

Figure 6:

Language for texting/chatting

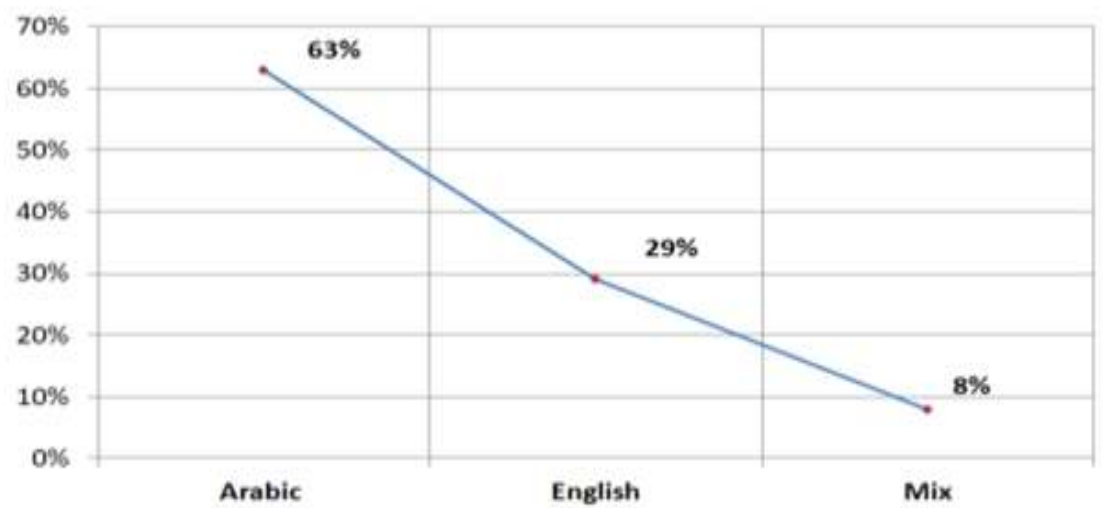

Part 3 of the questionnaire had 2 questions about awareness of health hazards associated with BB use and what the most common health hazard would be. Regarding awareness about health hazards associated with the use of BB phones, results showed that $54 \%$ of participants know that using BB phones too much would cause health problems and $45 \%$ do not. When participants were asked what the most common health hazards associated with the use of the BB phones would be, $45 \%$ reported that motor vehicle accidents would be a health hazards from the use of BB phones during driving, $22 \%$ reported that vision problems would be associated with the excessive use of BB phones, $20 \%$ reported that headaches could be a health problem associated with the use of $\mathrm{BB}$ phones, $8 \%$ reported that hearing problems would be a common health hazards, and $5 \%$ indicated that too much use of $\mathrm{BB}$ phone would cause brain problems. Results of common health problems associated with too much use of BB are presented in table2. 
Pattern of Use, Awareness of Health Hazards, and Effect on...

Table 2: Common health hazards associated with too much use of BB as reported by participants

\begin{tabular}{|l|l|}
\hline Item & $\begin{array}{l}\text { Percentage \% } \\
(\mathrm{N}=473)\end{array}$ \\
\hline $\begin{array}{l}\text { Do you know that too much use of BB can cause health hazards } \\
\text { Yes }\end{array}$ & $54 \%$ \\
No & $1 \%$ \\
Don't know & $45 \%$ \\
\hline What do you think common health hazards associated with too much & \\
BB use & $45 \%$ \\
MVA & $22 \%$ \\
Vision problems & $20 \%$ \\
Headache & $8 \%$ \\
Hearing & $5 \%$ \\
Brain Problems & \\
\hline
\end{tabular}

Regarding the effect of BB use on family relationships, results showed that $46 \%$ of participants said that they chat on their phones while sitting with their families, $44 \%$ reported that they put the phone aside while sitting with their families, and $10 \%$ reported that they turn their phones off while they are with the family. In addition, $26 \%$ reported that using $\mathrm{BB}$ too much might have negative effects on family relations, $37 \%$ revealed that they are trying to control their excessive use of BB phones while they are with their families, and $63 \%$ portrayed that they would buy BB for their kids. Results of BB use on family relationships are shown in figure 8 and 9.

Figure 8:

BB use and family Relationship

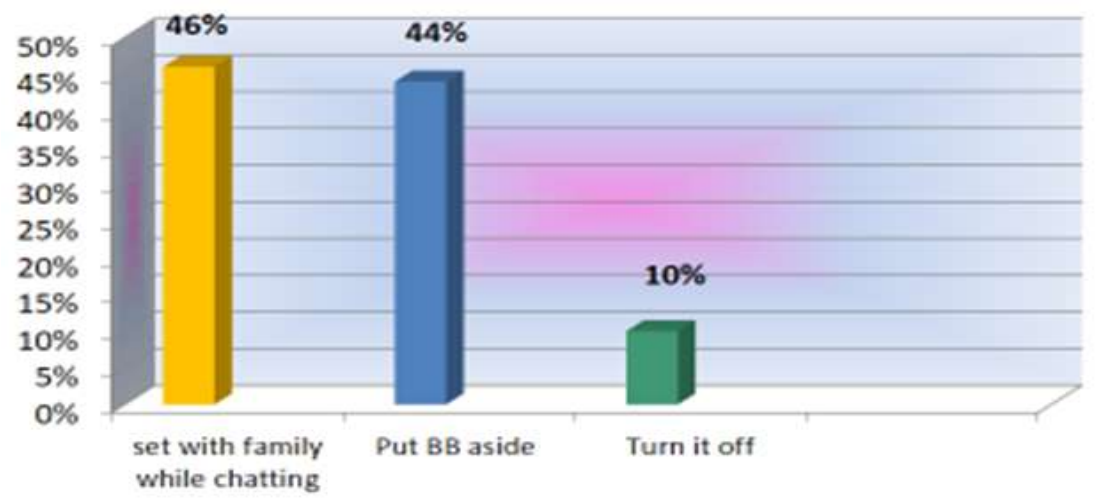

Figure 9

BB use and family Relationship

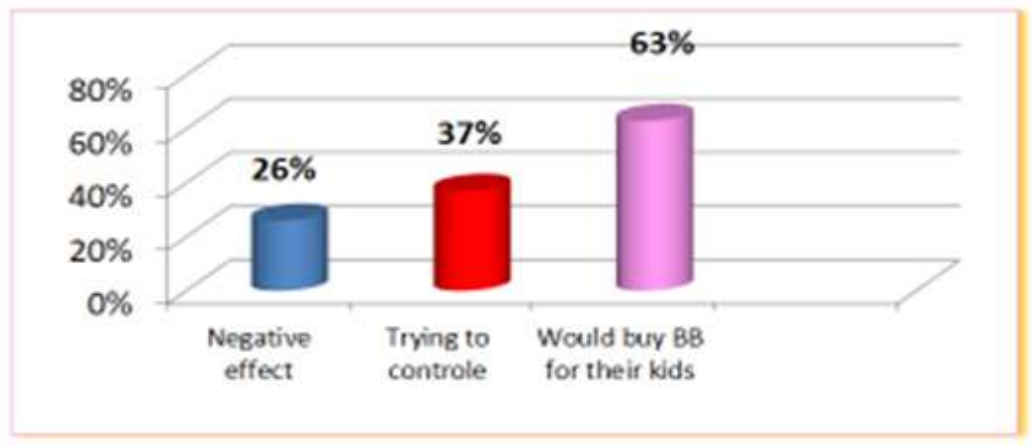

IV. Discussion

The pattern of BB use as measured in this study was not studied before. Pattern of BB use in this study was measured in terms of how important the BB phone is to participants, the time they use them, where they keep phones during sleep, whether they use BB during meal time or not, how often participants recharge internet connections, language of chatting, whether participants trust and confirm broadcast messages received on the BB phones. Results from this study indicated that people in different age groups use the BB extensively and consider their phones and internet connection as important to them. They use them frequently even during meal 
time and during family gathering and keep them close to bed or under pillow while sleeping. Similar results by (Krithika \& Vasantha, 2013) showed that youth and teens use their phone to the way that interrupt their daily life and develop over involvement with their phones. Aoki and Downes (2003) used qualitative and quantitative approaches to study young adults' attitudes towards cell phones. Their results indicated that although participants reported different attitudes toward the use of cell phones, and they were aware of negative effects of them, they said that their phones were important to them for many purposes.

One purpose of this study was to examine awareness of health hazards associated with use of BB phones. Results showed that almost half of participants know that use of BB might cause health problems. The common health hazards were mentioned by participants in this study as MVA, headache, vision, hearing, and brain problems. Results from Kumar, Chii, Way, Jetly, and Rajendaran (2011) showed that participants in their study reported that use of cell phone can cause many health problems such as headache, insomnia, distraction, and constipation. In addition, Chai, Chai and Tan (2000) indicated that headaches were the most prevalent health problem among hand held cellular phone users than non-users. Another study by Pendse and Zagade (2012) reported that juniors had average knowledge regarding physical hazards and poor knowledge regarding psychological health hazards associated with the use of cell phones. In addition, headache, tension, fatigue and sleep disturbance was reported by Al-Khlaiwi and Meo (2004) as health problems among cellular phone users.

Results from this study indicated that almost half of participants use their phone for chatting while sitting with the family, a considerable percentage eat fast and chat or eat and chat at the same time. A quarter of participants know that use of their BB phones during family time have a negative effects on family relationships. Research also revealed that although family gathering in meal time is good to build a positive effect on family life, being distracted during this time by using cell phones can weaken family relationships (Fitzpatrick, Edmunds, \& Dennison, 2007).

\section{Conclusion And Recommendations}

The purpose of the present study was to find out the pattern of mobile phones especially BB use, awareness of health hazards and effect on family relationships. The BB was chosen because it was more common among people at the time of data collection on 2012/2013. Results of the present study highlighted that although participants aware of health hazards associated with too much use of BB, they consider their phones very important to them and they use them most of the time even during classes, breaks and family gatherings. The life style in the Middle Eastern and Gulf area reported a tremendous change and the use of technology involved extensively. Without knowing the negative effects of technology on people life, the risks would outweigh the benefits. Considering these findings, interventional steps are needed to increase the awareness regarding hazards of mobile phone use. Further research is needed to examine people's attitudes towards the excessive use of new or advanced technology especially among youth. Research to examine effects of instructional intervention or modules on improving awareness regarding how people use their phones is also needed. One important result from this study was that MVA reported by $45 \%$ of participants that it would be a health hazard associated with the use of phones. Using phones during driving is a critical behavior and attention needs to be paid to protect people life.

\section{Limitations}

The present study did not look at attitude and perception regarding the use of BB and cellular phones in general. Attitude and perception could affect the way people think and knowing such concepts would also guide intervention to improve people's awareness. $19 \%$ of the sample in this study were school students, the effect of BB use on academic performance was not examined especially that $41 \%$ of participants in this study reported that they use their BB phones during classes. Such data would portray how nurse educator would help parents to instruct their youth on how to utilize their phones in a better way without effect on their academic achievement. An interesting piece of result from the current study showed that more than half of the participants who were parents would buy their kinds a BB phone. Uncovering reasons behind this result would help in developing a culturally aware campaign to improve people's awareness regarding the effective uses of such devices.

\section{References}

[1]. Al-Khlaiwi, T. and Meo, S.A. (2004). Association of Mobile Phone Radiation with Fatigue, Headache Dizziness, Tension and Sleep Disturbance in Saudi Population. Saudi Medical Journal, 25(6), 732-736.

[2]. Alzoman, K., \& Albagami, S. (2010). Al-watan, $3454 \quad$ (10). Retrieved from http://www.alwatan.com.sa/news/newsdetail.asp?issueno=3454\&id=140298.

[3]. Aoki, K., and Downes, E.J (2003). An analysis of young people's use of and attitudes toward cell phones. Telematics and Informatics, 20, (4), 349-364.

[4]. Chia SE, Chia HP, Tan JS. Prevalence of headache among hand held cellular Telephone users in Singapore. 2000 mar; 109(3):110.Available from www.jstor.org/stable/.

[5]. Fitzpatrick, E., Edmunds, L., \& Dennison, B. (2007). Positive Effects of Family Dinner are undone by Television Viewing. Journal of the American Dietetic Association, 01 (14), 666-671 
[6]. Kibi, K. (10 March 2010). [Saudi Arabia: 700\% increase in the demand for Blackberry services in 2009]. Alqabas, 13210. Retrieved from http://www.alqabas.com.kw/Article.aspx?id=584117\&date=10032010

[7]. Krithika, M. and Vasantha, S. (2013). The Mobile Phone Usage among Teens and Young Adults Impact of Invading Technology. International Journal of Innovation Research in Science, Engineering and Technology, 2(12), 7259-7265.

[8]. Kumar, L. R., Chii, K. D., Way, L. Jetly, C. y., and Rajendaran, V. (2011). Awareness of mobile phone hazards among university students in a Malaysian medical school. Openly accessible at http://www.scirp.org/journal/HEALTH/, 3(7), 406-415.

[9]. Pendse, N. and Zagade, D. (2012). Knowledge and Attitude Regarding Health Hazards of Mobile Phone Users among the Junior College Students. International Journal of Science and Research, 3(5), 2319-7064. 